\title{
Maternal Mortality Correlates by Nation
}

\author{
Gina Marie Piane \\ Community Health Department, National University, Costa Mesa, CA, USA \\ Email: gpiane@nu.edu
}

Received 24 August 2014; revised 22 September 2014; accepted 3 October 2014

Copyright (C) 2014 by author and Scientific Research Publishing Inc.

This work is licensed under the Creative Commons Attribution International License (CC BY). http://creativecommons.org/licenses/by/4.0/

c) (i) Open Access

\begin{abstract}
Background: This study reports the results of a secondary analysis of data provided by the World Health Organization to determine the correlates of maternal mortality among all reporting nations worldwide. Historically, maternal mortality ratios have declined in nations that provided a system for access to skilled care for the majority of its women. Currently, maternal mortality ratios are associated with access to skilled care as well as economic indicators, literacy, education, access to contraceptives, transportation and HIV prevalence. Methods: Descriptive statistics, bi-variate correlations and multiple linear regression analyses are reported using maternal mortality ratios as the dependent variable. In addition, an examination of countries that are exceptions to the regression is also reported. Results: Strong positive Pearson two-tailed correlations were found between MMR and infant mortality rate $(0.866)$, total fertility rate $(0.854)$, poverty rate $(0.756)$, and adolescent fertility rate $(0.710)$. Strong negative correlations were found between MMR and percentage of births attended by a skilled attendant $(-0.786)$, percentage of women using contraceptives $(-0.786)$, and adult literacy rate $(-0.710)$. Eighty-one percent of the variation in MMR can be explained by differences in IMR, percent of births attended by a skilled provider, percent of women using contraceptive, total fertility rate, adolescent fertility rate, adult literacy rate and poverty. Discussion: Examination of the correlates of maternal mortality gives direction to the effort to achieve the WHO's Millennium Development Goal of reducing maternal mortality by two-thirds from 1995-2015.
\end{abstract}

\section{Keywords}

Maternal Mortality, Millennium Development Goals, Women's Health

\section{Background}

\subsection{Maternal Mortality}

Maternal death is defined as "the death of a woman while pregnant or within 42 days of termination of preg- 
nancy, irrespective of the duration and site of the pregnancy, from any cause related to or aggravated by the pregnancy or its management but not from accidental or incidental causes" [1].

A Millennium Development Goal set by the World Health Organization is to reduce the current worldwide rate of maternal mortality of 400 per 100,000 live births by $75 \%$ by the year 2015 [2]. In order to achieve this goal, it will be necessary to dramatically reduce the rates in nations where the rates of women dying in childbirth are the highest in the world. Maternal mortality rates in the western world are stable and low; however, this has not always been true.

\subsection{Historic Correlates}

Maternal mortality rates were consistently high in the western world until they made a sharp decline in the 1930s [3]. The rates experienced today in sub-Saharan Africa averaging 684 deaths per 100,000 live births [4] have not been seen in the western world since the nineteenth century. During the last decade of the nineteenth century there was initially a dramatic decline in maternal mortality in northwestern Europe. Sharp declines in maternal mortality subsequently occurred in Great Britain, Ireland and the United States in the early twentieth century. Malaysia and Sri Lanka are the most recent nations to have experienced significant drops in maternal mortality toward the end of the twentieth century [3].

In Sweden from 1890 to 1895, the maternal mortality rate dropped from approximately 350 deaths per 100,000 live births to less than 200 [5]. This decline has been attributed to the widespread use of Listerian antisepsis in home deliveries. The same low levels occurred throughout northwestern Europe in Norway, Denmark and the Netherlands where midwives were traditionally well-trained and well-supervised. They consistently used antiseptic techniques since they were first introduced [6]. Sweden taught and trained professional midwives since early in the eighteenth century [7].

It wasn't until three decades later that a dramatic decline in maternal mortality occurred in England and Wales in the 1930s where the rate finally converged with Sweden's low rate of nearly 300 down from nearly 500 per 100,000 live births at the turn of the twentieth century. Loudon (2000) attributes the improved rates to the introduction of sulfonamides for treating streptococcus, "ergometrine, blood transfusions, penicillin, better training, better anesthesia, improved organization of obstetric services, less interference in normal labors and the decline in virulence of the streptococcus” [3]. A similar decline is documented in Ireland where the rate fell from 516 per 100,000 live births in 1933 to 257 in 1943 [8]. At this time Ireland was experiencing a widespread famine.

At the same time in the United States at the beginning of the twentieth century between 600 and 900 women died of pregnancy-related complications for every 100,000 live births [9]. By 1940 the rate had declined to less than 300. The Centers for Disease Control and Prevention [9] recognized that most of the maternal deaths were preventable because they were due to poor obstetric education and delivery practices. Inappropriate and excessive surgical and obstetrical interventions resulted in sepsis causing $40 \%$ of maternal deaths [10]. It is interesting to note that the United States at this time was experiencing the most devastating economic depression of its history.

Prior to the 1930s most deliveries were in homes. The training of midwives was not uniform. Some states had a history of training midwives since the mid nineteenth century while other states actually banned midwifery practice [11]. In the 1930s a call for action by the federal government for practice guidelines for hospital deliveries coincided with a shift from home births to hospital births. "During 1938-1948, the proportion of infants born in hospitals increased from 55\% to 90\%” [12]. Safer deliveries in hospital under aseptic conditions and provision of maternal care for the poor hastened the decline in maternal mortality after the 1930s. However, remarkable achievements were also made in rural areas. In rural Kentucky a group of midwives who traveled on horseback to assist deliveries achieved maternal mortality rates ten times lower than in the nearby city of Lexington and in the United States as a whole, despite the high level of poverty [3].

A third wave of improved maternal care occurred in Sri Lanka and Malaysia in the latter half of the twentieth century. In Sri Lanka maternal mortality rates dropped from 2000 per 100,000 live births in the 1930s to nearly 20 per 100,000 in the year 2000 [13]. Similarly, the rates in Malaysia declined from 550 in 1950 to less than 20 in 2000 [13]. The improvements are attributed to monitoring and analysis of levels and causes of maternal mortality, provision of integrated obstetric care by professional midwives, malaria control and family planning. A key element to their successes was removing financial barriers so that skilled attendance could reach more than $80 \%$ of the women giving birth. 
Historically, maternal mortality has been resistant to reduction despite decreases in other prominent causes of death, infection rate and changes in socioeconomic factors. Yet there are case studies of nations that demonstrate remarkable declines in maternal mortality in relatively short-time spans. It is evident that provision of quality services to pregnant women during delivery whether it is in the hospital or in homes in rural communities is the key to saving the lives of mothers. In northwestern Europe in the nineteenth century and in south Asia in the twentieth century, midwives were trained and integrated into the health care delivery system. In Great Britain and the United States in the 1930s, hospital deliveries were made safer and accessible to the majority of women. "Those countries that managed to provide professional obstetric care to cover the whole population, including poor and remote areas, achieved a relatively low level of maternal mortality earlier than the others” [14]. The lessons of the past can direct the efforts of the present to reach the World Health Organization's Millennium Development Goal of reducing maternal mortality worldwide by 75\% by 2015 .

\subsection{Current Correlates}

\subsubsection{Economic Factors}

Maternal mortality ratios have been associated with poverty rates [15]; however the relationship is complex requiring political will to tackle the issue [16]. In rural China, low income and literacy rates contributed to high maternal deaths due to their impact on the use of prenatal and obstetrical care [17]. Similarly, in Bangladesh, maternal care-seeking behavior was related to socioeconomic disparities in urban and rural settings [18]. An international study found that female education and literacy were moderate predictors of maternal mortality ratios [19]. Maternal mortality also has a negative effect on gross domestic product in Africa [20]. Many experts in the field of maternal health call for action to reduce poverty and empower women as a means to reduce maternal mortality [21].

\subsubsection{Skilled Care}

Maternal mortality also has been related to skilled care during delivery [22]; however the skill level of trained birth attendants has been the subject of debate [23]. Mbonye, et al. [24] found that the availability of midwives had the highest protective effect on maternal deaths in Uganda. In Nigeria, physician and midwife coverage was a key indicator [25]. In Bangladesh, the skilled midwives facilitated access to emergency care therefore contributing to the reduction in maternal deaths [26].

The provision of emergency obstetric care has decreased maternal deaths in Mali [27] and in Vietnam [28] but not in Nepal [29]. Lack of transport to emergency obstetric care contributed significantly to the maternal death rate in Mozambique [30] and in Thailand [31].

\subsubsection{Caesarean Section}

In an analysis of national, regional and global levels of births by Caesarean Section (CS), researchers associated with the World Health Organization (WHO) found a strong inverse relationship between CS rates and high maternal mortality levels [32]. An investigation in Nigeria found that the high prevalence of caesarean section refusal related to very poor maternal outcomes [33]. Researchers in the United States discovered that HIV-positive women are more likely than HIV-negative women to die as a result of caesarean section [34].

\subsubsection{Other Pregnancy-Related Outcomes}

An analysis of data provided by the WHO found a strong correlation between maternal mortality and stillbirth but not skilled delivery attendance of prenatal visits [35]. In its World Health Report, the WHO also cites availability of family planning services, skilled care before during and after birth, post abortion care and safe abortion as related to maternal mortality [4].

\subsubsection{Goal}

The goal of this study is to determine the correlates of maternal mortality ration among the nations that report health indicators.

\section{Methods}

This research describes a secondary analysis of data compiled by the World Health Organization (WHO) by na- 
tion. The dependent variable of analysis is Maternal Mortality Ratio (MMR). Twenty-two independent variables were chosen after reviewing the professional literature regarding maternal mortality. Nations with total population less than 100,000 were excluded from the analysis.

Descriptive statistics including means, minimum values and maximum values were reported along with the nation that the value represents. Bi-variate Pearson regression analyses were processed with missing values excluded. Strong correlations are determined if the coefficients are greater than 0.70 . Scatter plots were examined to identify outliers in the regressions and the nation represented.

The variables with strong bi-variate correlation were entered into a multiple linear regression analysis. Nations with a value reported for each variable were included in the analysis. Person coefficients and R-square values are reported. These analyses were conducted using SPSS version 15.

\section{Results}

\subsection{Descriptive Statistics}

Maternal Mortality Ratios (MMRs) are reported by the World Health Organization (WHO, 2008) for 168 of the 180 nations that they include in their data bases. The mean MMR is 326.65 per 100,000 live births (see Table 1 ). This ranges from 4 in Austria to 2000 in Sierra Leone. Table 1 lists the valid number, mean, minimum and maximum for the 22 independent variables (core health indicators) selected for this analysis.

Table 1. Descriptive statistics.

\begin{tabular}{|c|c|c|c|c|c|}
\hline Variable & Valid n & Missing n & Mean & Minimum & Maximum \\
\hline MMR & 168 & 12 & 326.65 & 4 Ireland & 2000 Sierra Leone \\
\hline IMR & 180 & 0 & 41.96 & 2 Iceland & 165 Afghanistan \\
\hline HIV M & 144 & 36 & 189.6 & 1 Japan & 7200 Liberia \\
\hline HIV P & 144 & 36 & 2276 & 52 Cuba & 34,457 Swaziland \\
\hline 1 PRENATAL & 77 & 103 & 78.96 & 27 Ethiopia & $\begin{array}{c}100 \text { Dominican Republic/Santa } \\
\text { Lucia }\end{array}$ \\
\hline 4 PRENATAL & 90 & 90 & 63.91 & 9 Rwanda & 100 Cuba \\
\hline ATTEND & 169 & 11 & 76.96 & 6 Ethiopia & 100 (37 Nations) \\
\hline CONTRA & 108 & 72 & 44.65 & 2.8 Chad & 90.2 China \\
\hline C SECT & 96 & 84 & 11.01 & 1 (9 Nations) & 32 Dominican Republic/Italy \\
\hline MD & 177 & 3 & 1.47 & 0.02 Niger & 5.91 Cuba \\
\hline $\mathrm{RN}$ & 177 & 3 & 3.45 & 0.11 Haiti & 15.2 Ireland \\
\hline MIDWIVES & 121 & 59 & 0.3243 & 0.00 Burundi/Cameroon & 4.27 Ireland \\
\hline$\%$ GDP & 176 & 4 & 6.153 & 1.6 Equatorial Guinea & $15.4 U S A$ \\
\hline PCH I\$ & 176 & 4 & 738.1 & 15.3 DR Congo & 6096.2 USA \\
\hline PCH US\$ & 176 & 4 & 447.8 & 0.2 DPR Korea & 5334.9 Luxemburg \\
\hline POP URBAN & 177 & 3 & 53.82 & 10 Burundi & 100 Singapore \\
\hline TFR & 179 & 1 & 3.142 & 1.1 Ukraine & 7.8 Timor Leste \\
\hline AFR & 164 & 16 & 6.013 & 0.2 RO Korea & 20.7 Niger \\
\hline ALR & 118 & 62 & 78.70 & 19.0 Mali & 99.8 Cuba \\
\hline SCHOOL M & 144 & 36 & 87.08 & 36 Djibouti & 100 (6 nations) \\
\hline SCHOOL F & 144 & 36 & 84.79 & 28 Djibouti & 100 Canada \\
\hline GNI & 158 & 22 & $10,406.84$ & 640 Burundi & 65,340 Luxemburg \\
\hline POVERTY & 75 & 105 & 16.19 & 2 (26 nations) & 76 Zambia \\
\hline
\end{tabular}




\subsection{Bi-Variate Analyses}

Strong positive Pearson two-tailed correlations were found between MMR and infant mortality rate (0.866), total fertility rate $(0.854)$, poverty rate $(0.756)$, and adolescent fertility rate $(0.710)$. Strong negative correlations were found between MMR and percentage of births attended by a skilled attendant $(-0.786)$, percentage of women using contraceptives $(-0.786)$, and adult literacy rate $(-0.710)$. Week negative correlations were found between MMR and cesarean section rate $(-0.657)$, percentage of females attending elementary school $(-0.649)$, density of physicians $(-0.619)$, percentage of males attending elementary school $(-0.617)$, percentage of population in urban areas $(-0.583)$, the percentage of women receiving at least four prenatal visits $(-0.541)$, density of nurses ( -0.529$)$, GNI $(-0.518)$, and health expenditure $(-0.420)$. Little or no correlation was found between MMR and, the prevalence rate of HIV (0.290), the percentage of women receiving at least one prenatal care visit $(-0.287)$, the percentage of GDP spent on health $(-0.267)$, the density of midwives $(-0.237)$, and the mean number of persons with HIV (0.199) (Table 2).

\subsection{Multiple Linear Regression}

A multiple linear regression was calculated to predict a nation's MMR based on infant mortality rate (IMR), percent of births attended by a skilled provider (ATTEND), percent of women using contraceptives (CONTRA), total fertility rate (TFR), adolescent fertility rate (AFR), adult literacy rate (ALR), and percent of population in poverty (POVERTY). A significant regression equation was found $(F(7,43)=501.329, p<0.0001)$, with an $R^{2}$ of 0.812 . A nation's MMR is equal to 501.32 per 100,000 live births + 2.82 (IMR) + 0.876 (ATTEND) -4.965 $($ CONTRA) + 27.234 (TFR) - 3.124 (AFR) - 3.407 (ALR) + 5.862 (POVERTY). Poverty rate is a significant independent variable in the equation.

Table 2. Bi-variate correlations of variables with maternal mortality rate.

\begin{tabular}{|c|c|c|c|}
\hline Variable & Valid n & Pearson correlation & Significance (two-tailed) \\
\hline IMR & 168 & $0.866^{* *}$ & 0.000 \\
\hline HIV M & 142 & $0.199^{*}$ & 0.018 \\
\hline HIV P & 142 & $0.290^{* *}$ & 0.000 \\
\hline 1 PRENATAL & 75 & $-0.287^{*}$ & 0.013 \\
\hline 4 PRENATAL & 88 & $-0.541^{* *}$ & 0.000 \\
\hline ATTEND & 160 & $-0.786^{* *}$ & 0.000 \\
\hline CONTRA & 107 & $-0.786^{* *}$ & 0.000 \\
\hline C SECT & 94 & $-0.657^{* *}$ & 0.000 \\
\hline MD & 167 & $-0.619^{* *}$ & 0.000 \\
\hline $\mathrm{RN}$ & 167 & $-0.529^{* *}$ & 0.000 \\
\hline MIDWIVES & 115 & $-0.237^{*}$ & 0.011 \\
\hline$\%$ GDP & 166 & $-0.267^{* *}$ & 0.001 \\
\hline PCH I\$ & 166 & $-0.420^{* *}$ & 0.000 \\
\hline PCH US\$ & 166 & $-0.335^{* *}$ & 0.000 \\
\hline POP URBAN & 167 & $-0.583^{* *}$ & 0.000 \\
\hline TFR & 167 & $0.854^{* *}$ & 0.000 \\
\hline AFR & 157 & $0.710^{* *}$ & 0.000 \\
\hline ALR & 114 & $-0.758^{* *}$ & 0.000 \\
\hline SCHOOL M & 135 & $-0.617^{* *}$ & 0.000 \\
\hline SCHOOL F & 135 & $-0.649^{* *}$ & 0.000 \\
\hline GNI & 150 & $-0.518^{* *}$ & 0.000 \\
\hline POVERTY & 75 & $0.756^{* *}$ & 0.000 \\
\hline
\end{tabular}

${ }^{*}$ Correlation is significant at the 0.05 level; ${ }^{* *}$ Correlation is significant at the 0.01 level. 


\section{Discussion}

\subsection{Descriptive Statistics}

There are great disparities among nations in MMRs and other core health indicators. The greatest disparities among nations are demonstrated in the numbers of persons living with HIV, where the mean in Liberia is 7200 times the mean in Japan and the prevalence of HIV where the rate in Swaziland is 662 times the rate in Cuba. Maternal Mortality Ratios are the second most disparate where 4 of every 100,000 live births in Ireland result in the death of the mother while 500 times more, 2000 per 100,000 live births, occur in Sierra Leone.

\subsection{Bi-Variate Analyses}

Reducing total fertility, poverty and adolescent fertility rates are likely to have a strong positive affect on MMRs. Likewise, increasing the percentage of women delivering babies in the presence of a trained attendant, increasing the percentage of women using contraceptives and increasing the adult literacy rate may also decrease MMRs significantly.

The results indicating little or no correlation between MMR and density of midwives can be somewhat misleading. In countries like the United States where the physician and nurse density is high, the density of midwives is reported as zero yet there is a relatively low MMR. In the absence of highly trained birth attendants such as physicians and nurses, the density of midwives may have a significant affect in reducing MMR.

The bi-variate analyses indicate a strong correlation between MMR and IMR. These are often not independent events. When a mother dies in childbirth or due to complications of pregnancy, the infant frequently suffers, as well. Independently reducing infant mortality may not affect the MMR however; programs to improve maternal and infant health usually seek to improve both infant and maternal outcomes at once.

\subsection{Outliers}

Examination of the scatter plots created by the bi-variate regression analysis has identified some nations that have high MMRs despite having similar values of independent variables as other nations. For example, United Republic of Tanzania has a relatively high MMR (1500 per 100,000 births) as compared to Gambia (540 per 100,000 births) and Madagascar (550 per 100,000 births) despite similar poverty rates (58\%, 59\% and 61\% respectively). Afghanistan and Sierra Leone have relatively high MMRs (1900 and 2000 respectively) as compared to Benin and Guinea (850 and 740) despite similarly low adult literacy rates (28.1\%, 35.1\%, 34.7\% and 29.5\% respectively). Malawi has a disproportionally high MMR (1800) compared to Tajikistan (100) even though they have similar contraceptive rates (32.5\% and 33.9\% respectively). Sierra Leone and Niger have high MMRs (2000 and 1600 respectively) compared to Papua New Guinea and Bangladesh (300 and 380 respectively) despite having very similar rates of attended births (42\% for both Sierra Leone and Papua New Guinea and 16\% and 13\% respectively for Niger and Bangladesh). Angola and Niger have relatively high MMRs (1700 and 1600) compared to Liberia (760) despite similar IMRs (154 per 1000 live births, 150 and 157 respectively). Also, Malawi has a high MMR (1800) compared to Azerbaijan (94) despite similar IMRs (78 and 74 respectively).

While Zimbabwe and Jordan have similar total fertility rates (3.4 per woman and 3.3), Zimbabwe has a much higher MMR (1100 compared to 41). Similarly, Sierra Leone and Congo have similar total fertility rates (6.5 and 6.3 respectively) however Congo has a much lower MMR (510 vs. 2000). A final outlier is Rwanda which has a high MMR (1400) compared to Thailand (100) though they have similar adolescent fertility rates (3.6 and 3.5 respectively). These outliers point out the need to examine both the positive factors that nations employ despite their profound challenges like high levels of poverty and high fertility rates and the negative factors that increase MMRs in the presence of more protective factors such as relatively low infant mortality.

\subsection{Multiple Linear Regression}

Eighty-one percent of the variation in MMR can be explained by differences in IMR, percent of births attended by a skilled provider, percent of women using contraceptive, total fertility rate, adolescent fertility rate, adult literacy rate and poverty. An unexpected finding in the multiple linear regression results is that adolescent fertility rates inversely affected MMRs in the regression equation. This is contrary to the results of the bi-variate regression where adolescent fertility rates had a strong positive correlation. 
The variable with the largest coefficient and therefore the greatest affect on MMR in the multiple linear regression is total fertility rate. The total fertility rate, the average number of children per woman, has declined dramatically in many nations throughout the world. According to demographic transition theories, it is usually preceded by reductions in infant mortality [36]. Total fertility rate also is related to the education and empowerment of girls and women. Women with more career choices often choose to have fewer children.

\subsection{Limitations}

A cross-sectional analysis such as this does not infer causation or temporal sequence of events. The data base is compiled by the WHO using estimation techniques for many variables including MMR since many countries have inadequate vital records. Using the nations as units of analysis ignores the disparities in these measures within nations.

\section{Conclusion}

In order for nations to experience a significant reduction in maternal mortality they must increase the percent of births attended by a skilled provider by training physicians, nurses or midwives and increasing access to care. They must also increase the percentage of women using contraceptives by making them affordable, accessible and acceptable. They need to improve adult literacy by investing in education. Reduction in total fertility rate traditionally does not occur until infant mortality rates are low and stable; however, if a nation can reduce the total fertility rate and infant mortality rate, MMRs will also recede. Nations must also work to fight poverty which goes hand in hand with maternal death.

\section{References}

[1] World Health Organization (1992) International Statistical Classification of Disease and Related Health Problems, Tenth Revision. World Health Organization, Geneva.

[2] World Health Organization (2007) World Health Report. World Health Organization, Geneva.

[3] Loudon, I. (2000) Maternal Mortality in the Past and Its Relevance to Developing Countries Today. The American Journal of Clinical Nutrition, 72, 241S-246S.

[4] World Health Organization (2005) World Health Report: Why Do So Many Women Still Die in Pregnancy and Childbirth? World Health Organization, Geneva.

[5] Hogberg, U. and Wall, S. (1986) Secular Trends in Maternal Mortality in Sweden from 1750 to 1980. Bulletin of the World Health Organization, 64, 79-84.

[6] Loudin, I. (1992) The Transformation of Maternal Mortality. British Medical Journal, 305, 1557-1560. http://dx.doi.org/10.1136/bmj.305.6868.1557

[7] Romlid, C. (1997) Swedish Midwives and Their Instruments in the Eighteenth and Nineteenth Centuries. In: Marland, H. and Rafferty, A., Eds., Midwives, Society and Childbirth: Debates and Contraversies in the Modern Period, Routledge, London, 38-60.

[8] Earner-Byrne, L. (2006) Managing Motherhood: Negotiating a Maternity Service for Catholic Mothers in Dublin, 1930-1954. Social History of Medicine, 19, 261-277. http://dx.doi.org/10.1093/shm/hkl038

[9] Centers for Disease Control and Prevention (1999) CDC on Infant and Maternal Mortality in the United States: 1900-99. Population and Development Review, 25, 821-826. http://dx.doi.org/10.1111/j.1728-4457.1999.00821.x

[10] Centers for Disease Control and Prevention (1998) Maternal Mortality-United States, 1982-1996. Morbidity and Mortality Weekly Report, 47, 705-707.

[11] Borst, C. (1988) The Training and Practice of Midwives: A Wisconsin Study. Bulletin of the History of Medicine, 62, 606-627.

[12] Children's Bureau (1950) Changes in Infant, Chidhood, and Maternal Mortality over the Decade 1939-1948: A Graphic Analysis. Social Security Association, Washington DC.

[13] Pathmanathan, I., Liljestrand, J., Martins, J., Rajapaksa, L., Lissner, C., De Silva, A.S., et al. (2003) Investing in Maternal Health: Learning from Malaysia and Sri Lanka, Health Nutrition and Population Series. The World Bank, Washington DC.

[14] De Brouwere, V. (2007) The Comparative Study of Maternal Mortality over Time: The Role of Professionalisation of Childbirth. Social History of Medicine, 20, 541-562. http://dx.doi.org/10.1093/shm/hkm070 
[15] Romero-Gutierrez, G., Espitia-Vera, A., Ponce-Ponce de Leon, A. and Huerta-Vargas, L. (2007) Risk Factors of Maternal Death in Mexico. Birth, 34, 21-25. http://dx.doi.org/10.1111/j.1523-536X.2006.00142.x

[16] van Dillen, J., Stekelenburg, J., Schutte, J., Walraven, G. and van Roosmalen, J. (2007) The Use of Audit to Identify Maternal Mortality in Different Settings: Is It Just a Difference between the Rich and the Poor? World Health \& Population, 9, 5-13. http://dx.doi.org/10.12927/whp.2007.18744

[17] Li, J., Luo, C., Deng, R., Jacoby, P. and de Klerk, N. (2007) Maternal Mortality in Yunnan, China: Recent Trends and Associated Factors. BJOG: An International Journal of Obstetrics \& Gynaecology, 114, 865-874. http://dx.doi.org/10.1111/j.1471-0528.2007.01362.x

[18] Koenig, M., Jamil, K., Streatfield, P., Saha, T., Al-Sabir, A., El Arifeen, S., Hill, K. and Haque, Y. (2007) Maternal Health and Care-Seeking Behavior in Bangladesh: Findings from a National Survey. International Family Planning Perspectives, 33, 75-82. http://dx.doi.org/10.1363/3307507

[19] McAlister, C. and Baskett, T. (2006) Female Education and Maternal Mortality: A Worldwide Survey. Journal of Obstetrics and Gynaecology Canada, 28, 983-990.

[20] Kirigia, J., Oluwole, D., Mwabu, G., Gatwiri, D. and Kainyu, L. (2006) Effects of Maternal Mortality on Gross Domestic Product (GDP) in the WHO African Region. African Journal of Health Sciences, 13, 86-95.

[21] Filippi, V., Ronsmans, C., Campbell, O., Graham, W., Mills, A., Borghi, J., et al. (2006) Maternal Health in Poor Countries: The Broader Context and a Call for Action. Lancet, 368, 1535-1541. http://dx.doi.org/10.1016/S0140-6736(06)69384-7

[22] Mpembeni, R., Killewo, J., Leshabari, M., Massawe, S., Jahn, A., Mushi, D. and Mwakipa, H. (2007) Use Pattern of Maternal Health Services and Determinants of Skilled Care during Delivery in Southern Tanzania. BMC Pregnancy and Childbirth, 7, 29.

[23] Harvey, S., Blandon, Y., McCaw-Binns, A., Sandino, I., Urbina, L., Rodriguez, C., et al. (2007) Are Skilled Birth Attendants Really Skilled? A Measurment Method, Some Disturbing Results and a Potential Way Forward. Bulletin of the World Health Organization, 85, 783-790. http://dx.doi.org/10.2471/BLT.06.038455

[24] Mbonye, A., Mutabazi, M., Asimwe, J., Sentumbwe, O., Kabarangira, J., Nanada, G. and Orinda, V. (2007) Declining Maternal Mortality Ratio in Uganda: Priority Interventions to Achieve the Millenium Development Goal. International Journal of Gynecology and Obstetrics, 98, 285-290. http://dx.doi.org/10.1016/j.ijgo.2007.05.019

[25] Inegbenebor, U. (2007) Conceptual Model for the Prevention of Maternal Mortality in Nigeria. Tropical Doctor, 37, 104-106. http://dx.doi.org/10.1258/004947507780609202

[26] Chowdhury, M., Botlero, R., Koblinsky, M., Saha, S., Dieltiens, G. and Ronsmans, C. (2007) Determinants of Reduction in Maternal Mortality in Matlab, Bangladesh: A 30-Year Cohort Study. Lancet, 370, 1320-1328. http://dx.doi.org/10.1016/S0140-6736(07)61573-6

[27] Otchere, S. and Kayo, A. (2007) The Challenges of Improving Emergency Obstretric Care in Two Rural Districts in Mali. International Journal of Gynecology and Obstetrics, 99, 173-182. http://dx.doi.org/10.1016/j.ijgo.2007.07.004

[28] Otchere, S. and Bihn, H. (2007) Strengthening Emergency Obstetric Care in Thanh Hoa and Quang Tri Provinces in Vietnam. International Journal of Gynecology and Obstetrics, 99, 165-172. http://dx.doi.org/10.1016/j.ijgo.2007.07.005

[29] Rath, A., Basnett, I., Subedi, H., Thomas, D. and Murray, S. (2007) Improving Emergency Obstetrical Care in a Context of Very High Maternal Mortality: The Nepal Safer Motherhood Project 1997-2004. Reproductive Health Matters, 15, 72-80. http://dx.doi.org/10.1016/S0968-8080(07)30329-7

[30] Granja, A., Machungo, F. and Bergstrom, S. (2000) Avoidability of Maternal Death in Mozambique: Audit and Retrospective Risk Assessment in 106 Consecutive Cases. African Journal of Health Sciences, 7, 83-87.

[31] Liabsuetrakul, T., Peeyababjarassri, K., Tassee, S., Sanguanchua, S. and Chaipinitpan, S. (2007) Emergency Obstetric Care in the Southernmost Provinces of Thailand. International Journal for Quality in Health Care, 19, 250-256. http://dx.doi.org/10.1093/intqhc/mzm023

[32] Bertran, A., Merialdi, M., Lauer, J., Bing-Shun, W., Thomas, J.V. and Wagner, M. (2007) Rates of Caesarean Section: Analysis of Global, Regional and National Estimates. Paediatric and Perinatal Epidemiology, 21, 98-113. http://dx.doi.org/10.1111/j.1365-3016.2007.00786.x

[33] Chigbu, C. and Iloabchie, G. (2007) The Burden of Caesarean Section Refusal in a Developing Country Setting. BJOG: An International Journal of Obstetrics \& Gynaecology, 114, 1261-1265. http://dx.doi.org/10.1111/j.1471-0528.2007.01440.x

[34] Louis, J., Landon, M., Gersnoviez, R., Leveno, K., Spong, C., Rouse, D., et al. (2007) Perioperative Morbidity and Mortality among Human Immunodeficiency Virus Infected Women Undergoing Cesarean Delivery. Obstetrics and Gynecology, 110, 385-390. http://dx.doi.org/10.1097/01.AOG.0000275263.81272.fc 
[35] McClure, E., Goldenberg, R. and Bann, C. (2007) Maternal Mortality, Stillbirth and Measures of Obstetric Care in Developing and Developed Countries. International Journal of Gynecology and Obstetrics, 96, 139-146. http://dx.doi.org/10.1016/j.ijgo.2006.10.010

[36] Merson, M., Black, R. and Mills, A. (2005) International Public Health: Diseases, Programs, Systems and Policies. Jones and Bartlett, Boston. 
Scientific Research Publishing (SCIRP) is one of the largest Open Access journal publishers. It is currently publishing more than 200 open access, online, peer-reviewed journals covering a wide range of academic disciplines. SCIRP serves the worldwide academic communities and contributes to the progress and application of science with its publication.

Other selected journals from SCIRP are listed as below. Submit your manuscript to us via either submit@scirp.org or Online Submission Portal.
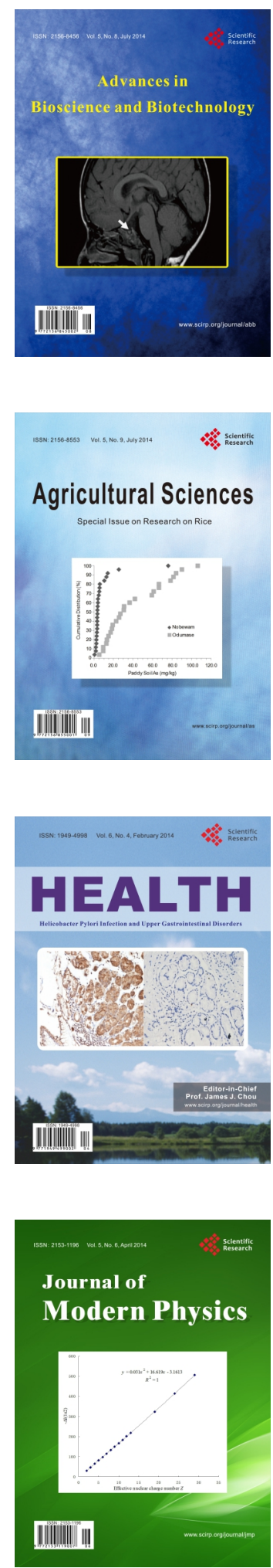
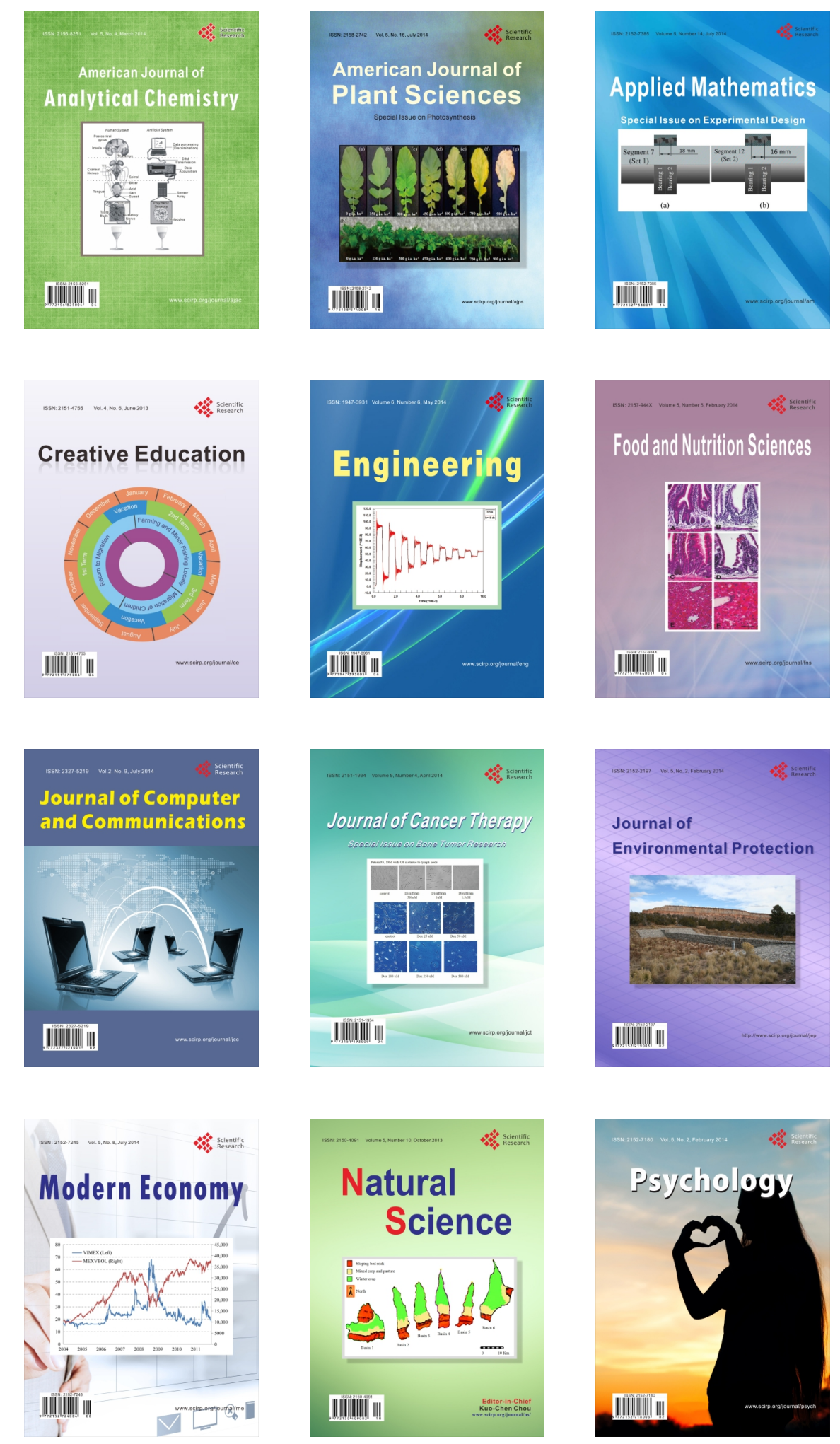